\title{
Stage IB Cervix
}

National Cancer Institute

\section{Source}

National Cancer Institute. Stage IB Cervix. NCI Thesaurus. Code C96240.

A stage term referring to invasive cervical cancer that is confined to the cervix without lymph node involvement. It includes: IB (T 1b, N0, M0); IB1(T1 b1, N0, M0); IB2 (T 1b2, N0, M0). T 1 b: Clinically visible lesion confined to the cervix or microscopic lesion greater than $\mathrm{T} 1 \mathrm{a} / \mathrm{IA} 2$. T1 b1: Clinically visible lesion $4.0 \mathrm{~cm}$ or less in greatest dimension. T1b2: Clinically visible lesion more than $4.0 \mathrm{~cm}$ in greatest dimension. N0: No regional lymph node metastasis. M0: No distant metastasis. (partially adapted from AJCC) 